\title{
Simultaneous Treatment of Vestibular Schwannoma and Concurrent Middle Ear Disease Using the Enlarged Translabyrinthine Approach
}

\author{
Hae Eun Noh ${ }^{1}$, Ho Young Lee ${ }^{1}$, Gina $\mathrm{Na}^{2}{ }^{\mathbb{D}}$, and In Seok Moon ${ }^{1}$ \\ ${ }^{1}$ Department of Otorhinolaryngology, Yonsei University College of Medicine, Seoul; and \\ ${ }^{2}$ Department of Otorhinolaryngology, Ilsan Paik Hospital, Inje University College of Medicine, Goyang, Korea
}

\author{
확장 경미로 접근법을 사용한 청신경종양과 중이병변 동시 제거술 \\ 노혜은 ${ }^{1} \cdot$ 이호영 ${ }^{1} \cdot$ 나지나 $^{2} \cdot$ 문인석 $^{1}$ \\ 연세대학교 의과대학 이비인후과학교실, ${ }^{1}$ 인제대학교 의과대학 일산백병원 이비인후과학교실 ${ }^{2}$
}

\author{
Received August 1, 2020 \\ Revised October 23, 2020 \\ Accepted November 2, 2020 \\ Address for correspondence \\ Gina Na, MD \\ Department of Otorhinolaryngology, \\ Ilsan Paik Hospital, \\ Inje University College of Medicine, \\ 170 Juhwa-ro, Ilsanseo-gu, \\ Goyang 10380, Korea \\ Tel +82-31-910-7250 \\ Fax +82-31-910-7747 \\ E-mail kalosophiana@gmail.com
}

Unilateral presentation of vestibular schwannoma with concurrent chronic middle ear disease or cholesteatoma is rare. We report a series of patients with ipsilateral chronic middle ear disease and vestibular schwannoma, which were simultaneously removed via the enlarged translabyrinthine approach. All tumors were near-totally removed, and middle ear disease was completely excised; there were no major postoperative complications such as cerebrospinal fluid leakage, cholesteatoma recurrence, or meningitis. If hearing preservation of the affected ear is not necessary, simultaneous surgical removal of both pathologies is more convenient than staged treatment. The enlarged translabyrinthine approach can achieve complete treatment with one corridor. Korean J Otorhinolaryngol-Head Neck Surg 2021;64(5):344-9

\section{서 론}

청신경종양은 소뇌 교각에 발생하는 가장 흔한 양성 종양 (85\%)으로, 감각신경성 난청 및 현훈을 유발하고, 내이도를 침범하거나, 소뇌 및 뇌간, 소뇌 교각에 위치한 뇌신경 압박 으로 여러 신경학적 증상을 초래할 수 있다. 청신경종양의 치 료의 선택에 대해서 현재 명확한 합의에 이르지 못했으나, 크 게는 경과관찰, 정위 방사선치료, 수술로 구분되고, 환자의 연령, 종양의 크기 및 위치, 잔존 청력, 신경학적 증상과 주치 의 및 기관의 정책에 기반하여 치료를 진행하고 있다. ${ }^{1)}$ 청신 경종양의 수술적 치료를 위해 종양의 크기를 판단하는 기준 은 여러가지가 있는데, 그 중에서도 내이도 외부로 확장된 정

This is an Open Access article distributed under the terms of the Creative Commons Attribution Non-Commercial License (https://creativecommons.org/licenses/by-nc/4.0) which permits unrestricted non-commercial use, distribution, and reproduction in any medium, provided the original work is properly cited.
도와 종양의 뇌간 압박 정도를 기반으로 청신경종양의 크기 를 평가하는 Koos 분류법이 가장 많이 사용된다(Table 1).,2)

진주종은 점막으로 구성된 중이강 내로 각화편평상피가 침 입하여 각질을 축적하며 자라나는 질환으로, 후천적인 경우 이관기능부전과 반복적인 중이 내 감염의 결과로 발생한다. 주위 골조직을 파괴하며 자라나는 양상이므로 병변이 진행 될 시 내이 및 뇌내 침범할 수 있으며, 따라서 난청 이외에도 현훈, 안면신경 마비, 두개 내 합병증 등을 유발할 수 있기 때 문에, 대부분 적절한 시기에 수술적 치료를 필요로 한다. ${ }^{3)}$

진주종의 유병률은 연간 10만 명당 9.2명으로 보고되고 있 고, ${ }^{4)} 2.7 \sim 12 \%$ 에서는 미로 누공이 발생하기도 한다.5,6) 청신경 종양의 경우 연간 100만 명당 12 19.4명의 유병률을 보이고 있다.8) 따라서, 어지럼을 유발할 수 있는 미로 누공이 동반 된 진주종과 청신경종양이 동시에 발생할 가능성은 연간 약 280 억 명 중 1 명으로 계산해 볼 수 있고, 이는 전 세계에서 
4년에 1명 빈도로 추측해 볼 수 있는 드문 질환이다.9) 또한 일측성 난청 또는 현훈이 진주종이나 만성 중이염 증상으로 오인되어 청신경종양의 진단 자체가 늦어질 가능성이 있다. ${ }^{10)}$ 만성중이염, 특히 진주종성 중이염이 동반된 청신경종양을 한 번의 수술적 치료만으로 제거 후 장기적인 예후를 보고한 문헌은 현재까지 없다. 따라서, 기존의 경미로 접근술에 외이

Table 1. The Koos grading system

\begin{tabular}{cc}
\hline Koos grade & Tumor size \\
\hline I & Tumor involves only the internal auditory canal \\
Tumor extends into the cerebellopontine angle, \\
but do not encroach on the brainstem \\
III Tumor fills the entire cerebellopontine angle, but \\
do not displace the brainstem \\
Large tumor displaces the brainstem and \\
adjacent cranial nerves
\end{tabular}

도 후벽 절제술을 추가하여 수술 시야와 접근공간을 넓혀 큰 청신경종양의 수술을 용이하게 하는 확장된 경미로 접근 법(enlarged translabyrinthine approach)을 ${ }^{11)}$ 통해 종양과 중이병변을 동시에 제거할 수 있었던 증례들을 보고하여 저 자들의 경험을 공유하고자 한다.

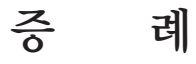

\section{증례 1}

36세 남자 환자가 간헐적인 우측 귀의 이루 및 통증을 주 소로 내원하였다. 8년전 타병원에서 우측 귀의 진주종으로 외이 후벽 보존 유양동 삭개술(canal wall up tympanomastoidectomy)을 시행 받았으며, 당시 청신경종양(medium sized vestibular schwannoma)을 발견하고 감염 예방을 위해 단
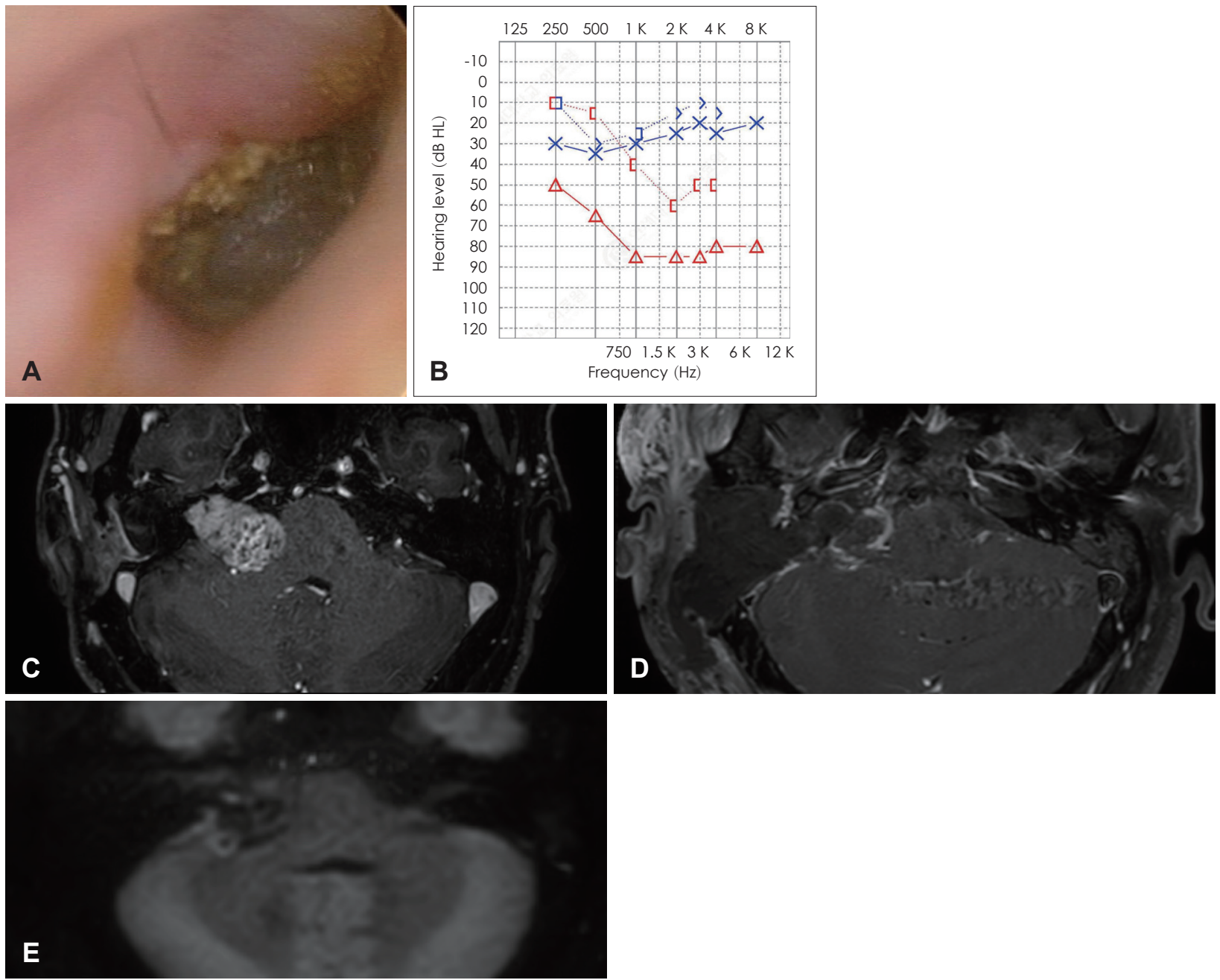

Fig. 1. Case 1. Right eardrum. The bulging of the superior posterior part of the external auditory canal can be seen (A). Pure tone audiometry shows right severe mixed hearing loss (B). Preoperative T1W FS MRI enhanced with gadolinium shows a $32 \times 20 \mathrm{~mm}$ sized tumor in internal auditory canal and cerebellopontine angle (C). Postoperative T1W FS MRI showing no growth of vestibular schwannoma nor chronic otitis media (D). Postoperative turbo spin-echo diffusion weighted image showing no recurrence of cholesteatoma (E). T1W FS: T1 weighted fat suppressed. 
계적 수술을 계획하였으나 진주종 수술만 시행했던 과거력이 있다. 본원에서 시행한 순음청력검사상 좌측은 $30 \mathrm{dBHL}$, 우측은 $80 \mathrm{dBHL}$ 였으며, 종양의 크기는 8 년 전 $22 \times 21 \mathrm{~mm}$ 의 크기에서 $32 \times 20 \mathrm{~mm}$ 으로 증가한 Koos grade IV에 해당 하였다(Fig. $1 \mathrm{~A}-\mathrm{C}$ ). 진주종과 종양을 동시에 제거하기 위해 확장된 경미로 접근법을 통한 종양 절제를 결정하였다. 수술 시야에서 외이도 후벽의 일부는 보존이 되어 있었으나, 상고 실 및 중이강 전체를 침범한 진주종이 관찰되었다. 진주종의 재발과 뇌척수 유출을 방지하기 위해 측두골의 모든 함기 세 포와 점막 및 외이도 후벽을 제거하는 아전 추체절제술(subtotal petrosectomy)를 시행(Fig. 2A)하고 외이도의 피부는 봉합하여 맹관화(cul-de-sac closure)하였다(Fig. 2C and D). 경미로 접근법으로 내이도의 270도 주변 골편을 제거하고 후 두개와의 경막을 절개하여 두개강 내(intracranial) 종양 전체
를 노출하였고(Fig. 2B), 종양의 근전절제(near-total resection) 이후 복부 지방을 이용하여 이관과 후두개와 및 중이강 내에 빈 공간을 폐쇄하였다. 종양 제거에는 약 6시간 소요되 었으며, 수술 후 8개월째까지 안면마비, 뇌척수액 누출, 상처 감염 및 자기공명영상 $(\mathrm{MRI})$ 을 통한 진주종의 재발과 잔존 종양의 크기 증가는 관찰되지 않았다(Fig. $1 \mathrm{D}$ and E).

\section{증례 2}

55세 남자 환자가 우측 돌발성 난청의 원인감별을 위해 시 행한 측두골 자기공명영상에서 우측의 청신경종양을 발견하 여 내원하였다. 순음청력검사상 좌측은 정상, 우측은 전농이 었으며, 종양의 크기는 $35 \times 40 \mathrm{~mm}$ Koos grade IV였다. 측 두골 전산화단층영상에서 우측 측두골의 함기 세포와 유양 동(antrum)이 매우 수축되어 있고 중이강 내로 환기가 되지
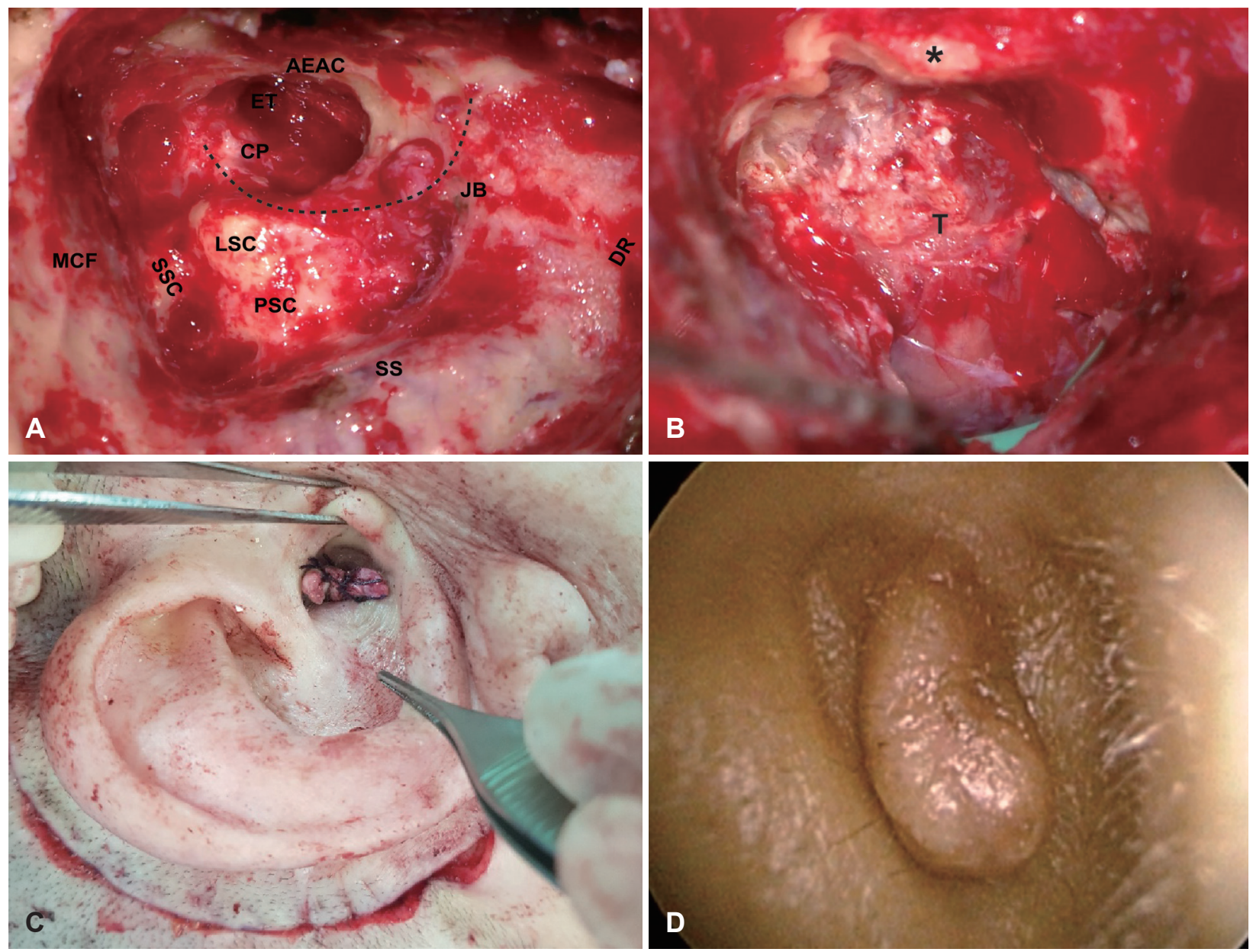

Fig. 2. Case 1. A surgical field during subtotal petrosectomy. Removing the posterior canal wall extends the surgical field and enhances light transmission from microscope (A). After 270-degree exposure around the IAC, intracranial tumor is exposed (B). For enlarged translabyrinthine approach, subtotal petrosectomy including EAC closure is the first step, and EAC is closed as cul-de-sac (C). The skin of the ear canal is well healed without the recurrence of cholesteatoma one year after surgery (D). Dotted line and asterisk: facial nerve. AEAC: the anterior wall of EAC, CP: cochleriform process, DR: digastric ridge, ET: eustachian tube, JB: jugular bulb, LSC: lateral semicircular canal, MCF: middle cranial fossa dura, PSC: posterior semicircular canal, SS: sigmoid sinus, SSC: superior semicircular canal, T: tumor in IAC, IAC: internal auditory canal, EAC: external auditory canal. 

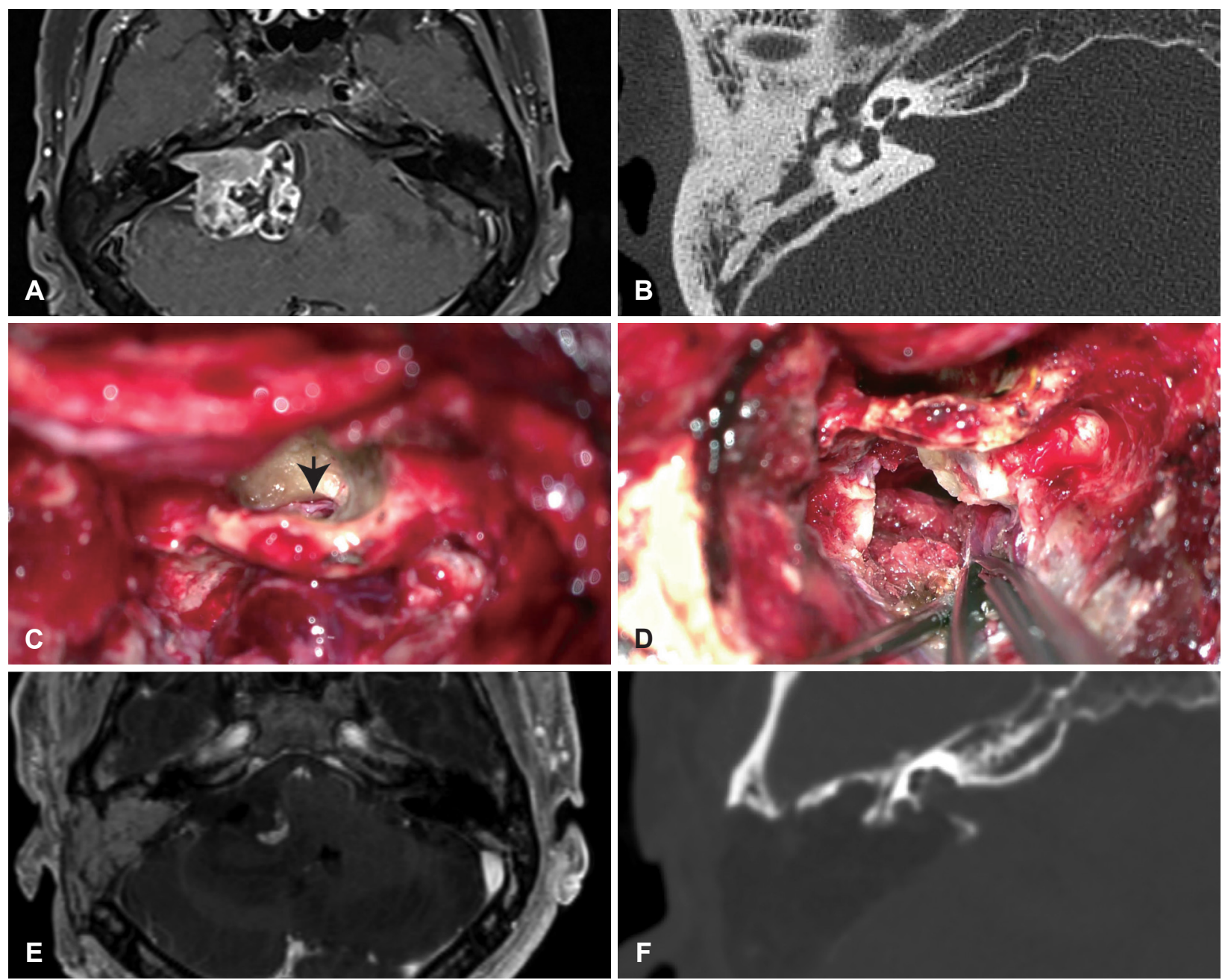

Fig. 3. Case 2. Pre-operative T1 weighted fat suppressed MRI shows a $35 \times 40 \mathrm{~mm}$ sized tumor occupying the right IAC and cerebellopontine cistern. The tumor causes adjacent brain stem indentation (A). Pre-operative CT showing constricted mastoid and soft tissue opacity filling the middle ear (B). The surgical view through the middle ear cavity beyond the mastoid segment of the facial nerve. The tumor of the fundus (arrow) is peeled off after the basal turn of cochlea is drilled out (C). The posterior fossa dura is open, and the tumor is being resected. The intracranial facial nerve is not projected because it is obscured by the tumor (D). Post-operative T1 weighted MRI. Posterior dura mater was repaired, and the mastoid cavity was filled with the fat strip (E). Postoperative CT shows bony defect of IAC and basal turn of the cochlea (F). IAC: internal auditory canal.

않으며 연조직 음영이 차 있는 만성 중이염이 확인되었다 (Fig. 3A and B). 또한 종양이 와우의 기저회전 가까이 내이 도 저(fundus)까지 팽창되어 있어 시야를 확보하고, 염증조직 과 종양을 동시에 제거하고자 확장된 경미로 접근법을 통한 종양 절제를 결정하였다. 본 환자에서는 내이도 저의 종양을 떼어 내기 위해 와우 융기(cochlear promontory)의 추가적 인 골삭개를 통해 시야확보 후 종양을 근전절제 하였다(Fig. $3 \mathrm{E}$ and F). 이후 경막을 재건하고 복부 지방을 이용하여 술 부를 완전 폐쇄하였다. 수술 직후 제거된 종양 주변 소뇌 지 혈부위의 경도 경색소견과 House-Brackmann grade IV의 안면마비가 관찰되었으나 안면마비는 수술 후 1년째 grade I-II로 회복되었으며 그 외에 특별한 신경학적 후유증은 없
었다. 종양 제거에는 약 8 시간 소요되었고, 수술 후 1 년째 뇌 척수액 누출, 상처 감염, 중이염 및 잔존종양의 크기 증가는 관찰되지 않았다.

\section{증례 3}

71세 여자 환자가 1 년만에 크기가 $7 \mathrm{~mm}$ 증가한 좌측의 청 신경종양을 발견하여 내원하였다. 종양의 크기는 $34 \times 29 \mathrm{~mm}$ 로 Koos grade IV였다(Fig. 4A and B). 50년 전 만성 중이염 으로 좌측의 외이 후벽 제거 유양동 삭개술을 시행 받았으 며, 내원 시 좌측의 고막천공 및 이루가 관찰되었고 청력은 전농이었다. 만성 중이염과 종양을 동시에 제거하기 위해 확 장된 경미로 접근법을 통한 종양의 아전절제(subtotal resec- 

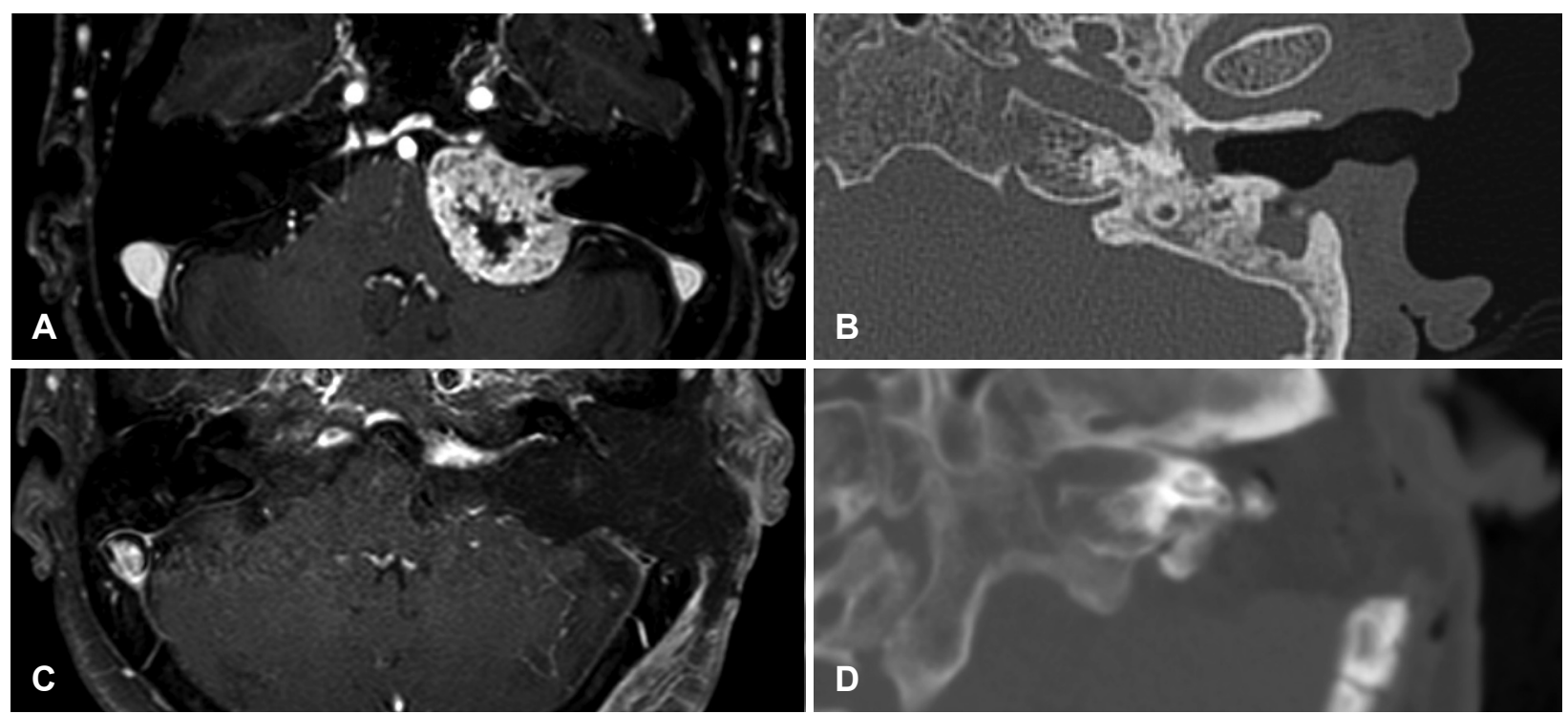

Fig. 4. Case 3. Pre-operative T1W FS MRI shows a $34 \times 29 \mathrm{~mm}$ sized tumor in the left IAC and cerebellopontine cistern (A). Pre-operative CT showing no posterior wall of external auditory canal and bony overgrowth on the facial ridge (B). Post-operative T1W FS MRI. The tumor is subtotally removed (C). Post-operative CT shows completely eradicated petrous bone (D). T1W FS: T1 weighted fat suppressed.

tion) 절제를 시행하였다. 종양의 제거에는 약 7시간 소요되 었고, 수술 후 1년 2개월째 합병증 및 잔존 종양의 크기 증가 는 관찰되지 않았다(Fig. 4).

\section{고 찰}

청신경종양과 만성 중이 질환이 동시에 같은 귀에 발생하 는 경우는 매우 드물다. 청신경종양과 진주종이 반대측에서 각각 발생한 것으로 보고된 증례는 Khosla 등'2)과 Ogungbo 등 $^{13)}$ 이 보고한 바 있다. 두가지 질환 모두 점진적인 청력저하 를 유발하기 때문에, 치료계획 수립에 있어 병변의 제거뿐만 아니라 청력의 보존과 재활이 중요하다. 청신경종양과 진주 종이 동측에 동반된 증례로 Zwierz 등'이 진주종 제거를 위 해 개방동 유양 돌기 절제술을 시행하고 청신경종양에 감마 나이프(Gamma Knife radiosurgery)를 시행한 바를 보고한 바 있으며, Kucharski 등ㄴ)이 진주종과 청신경종양이 동측에 동반된 환자에서 경 이낭 접근법(transotic approach)을 통해 일단계로 병변을 성공적으로 제거한 증례를 보고하였다.

청신경종양과 중이 염증성질환, 특히 진주종이 동측에 동 반된 경우에는 치료계획 수립 시에 두가지 질환 모두에 적절 한 치료가 이루어질 수 있도록 다방면으로 충분한 고려가 필 요하다. 첫 번째 증례는 최초에 타병원에서 단계별 수술을 계 획하였으나 진주종만을 제거하고 추적 관찰이 자의 중단되었 던 증례로, 종양의 크기가 Koos grade III에서 grade IV까지 커졌으며 진주종 또한 재발한 상태로 내원하였다. 두 번째 증 례도 내원 당시 종양의 크기가 Koos grade IV로 거대하였고
이미 종양 내 낭성화가 진행된 상태였다. 마지막 증례는 고령 의 환자로 중이염의 수술 후 감마나이프 등을 고려하였으나, 종양의 자라는 속도가 빠르고 종양 내에 낭성화가 진행된 상 태로 전신 건강상태가 양호하여 논의 후 동시에 제거였다.

상기 모든 증례에서 종양의 크기는 Koos grade IV로 크기 가 컸기 때문에 진주종 수술 후 단계적인 감마나이프는 효과 의 장담이 어려웠다. 수술 부위 감염 방지를 위해 진주종 수술 후 2단계로 구불정맥굴 뒤접근법(retrosigmoid approach)을 통한 종양절제를 고려할 수 있으나, 중이강으로 수술부위 교 통의 가능성은 여전히 존재한다. 또한 청력 보존의 측면에서 도 본 증례와 같이 사회 적응 청력(non-serviceable hearing) 을 소실한 환자에서는 중이염 치료를 선행하는 것이 큰 이득 없이 치료 시기만 늦출 위험성이 있다고 판단하였다. 중이 질 환을 완전하게 제거하기 위해 외이도 후벽 삭개 시행이 필요 하거나(증례 1,2 ), 종양의 크기와 위치 때문에 넓은 시야의 확보가 필요한 경우(증례 2), 또는 기존에 후벽 삭개 유양동 절제술을 시행 받았던 경우(증례 3), 확장된 경미로 절제술로 횔씬 좋은 시야와 수술 공간을 확보할 수 있으며 수술의 횟 수를 줄이고 총 치료 기간과 비용을 단축할 수 있다는 장점 이 있다. 이와 같은 이유로 술자는 중이 염증질환이 동반된, 상기 증례들에 대한 치료법으로 확장된 경미로 절제술을 선 택하였다.

확장된 경미로 절제술은 전술한 장점에도 불구하고 중이 염증성 병변의 제어가 완벽히 이루어지지 않을 경우 두개 강 내로 염증이나 진주종이 파급될 위험성을 가진다. 진주종의 재발, 중이 염증의 두개강 내 확산, 그리고 수술 후 뇌척수액 
유출을 방지하기 위해서 병변은 물론 측두골의 모든 함기 세 포와 중이강의 점막, 고막을 포함한 외이도 피부를 완벽하게 제거하는 것이 필수적이다. 기존의 경미로 절제술과 달리 외 이도를 폐쇄해야 하는 단점도 존재한다. 또한, 본 증례들의 수술 후 추적 관찰 기간은 8개월 1년 2개월로 수술 후 진주 종, 만성 중이염, 잔존 청신경종양의 재성장에 대한 장기적인 평가에는 한계가 있어 확산 강조 영상(diffusion weighted) $\mathrm{MRI}$ 를 포함하여 향후 면밀한 추적 관찰 예정이다.

전통적으로 중이강 내의 감염소견이 있을 때 경미로 접근 법은 절대적인 금기증으로 여겨져 왔다. ${ }^{15)}$ 하지만 경험 있는 술자가 염증을 확실히 제어하고 후두개와와 중이강 사이의 교통이 발생하지 않도록 두 공간을 확실히 분리한다면, 확장 된 경미로 절제술은 더 좋은 시야에서 치료 기간과 수술 시 간을 줄이면서 효율적으로 동시에 두가지 목적을 달성할 수 있는 좋은 대안이 될 수 있다.

\section{Acknowledgments}

None.

\section{Author Contribution}

Conceptualization: Hae Eun Noh, Gina Na, In Seok Moon. Data curation: Hae Eun Noh, Ho Young Lee, Gina Na. Formal analysis: Gina Na, In Seok Moon. Supervision: Gina Na, In Seok Moon. Visualization: Gina Na. Writing - original draft: Hae Eun Noh. Writing_-review \& editing: Gina Na, In Seok Moon.

\section{ORCID}

Gina Na

https://orcid.org/0000-0001-8111-2124

\section{REFERENCES}

1) Goldbrunner R, Weller M, Regis J, Lund-Johansen M, Stavrinou P, Reuss D, et al. EANO guideline on the diagnosis and treatment of vestibular schwannoma. Neuro Oncol 2020;22(1):31-45.

2) Koos WT, Day JD, Matula C, Levy DI. Neurotopographic considerations in the microsurgical treatment of small acoustic neurinomas. J Neurosurg 1998;88(3):506-12.

3) Rosito LS, Netto LF, Teixeira AR, da Costa SS. Classification of cholesteatoma according to growth patterns. JAMA Otolaryngol Head Neck Surg 2016;142(2):168-72.

4) Olszewska E, Wagner M, Bernal-Sprekelsen M, Ebmeyer J, Dazert $\mathrm{S}$, Hildmann H, et al. Etiopathogenesis of cholesteatoma. Eur Arch Otorhinolaryngol 2004;261(1):6-24.

5) Rosito LPS, Canali I, Teixeira A, Silva MN, Selaimen F, Costa SSD. Cholesteatoma labyrinthine fistula: Prevalence and impact. Braz J Otorhinolaryngol 2019;85(2):222-7.

6) Manolidis S. Complications associated with labyrinthine fistula in surgery for chronic otitis media. Otolaryngol Head Neck Surg 2000;123(6):733-7.

7) Babu R, Sharma R, Bagley JH, Hatef J, Friedman AH, Adamson C. Vestibular schwannomas in the modern era: Epidemiology, treatment trends, and disparities in management. J Neurosurg 2013;119(1): 121-30.

8) Stangerup SE, Tos M, Thomsen J, Caye-Thomasen P. True incidence of vestibular schwannoma? Neurosurgery 2010;67(5):1335-40; discussion 1340.

9) Zwierz A, Masna K, Burduk P. Middle-ear cholesteatoma coexisting with labyrinthine fistula and vestibular schwannoma. Eur Arch Otorhinolaryngol 2020;277(4):999-1003.

10) d'Ecclesia A, Contucci A, Di Girolamo S, Meglio M, Paludetti G. Chronic otitis media masking coexistent acoustic neuroma. J Otolaryngol 2002;31(1):49-52.

11) Zhu ZJ, Zhu WD, Chen HS, Wang ZY, Wu H. Decision making in dissection range of temporal bone: Refinements to enlarged translabyrinthine approach. Eur Arch Otorhinolaryngol 2016; 273(5):1115-21.

12) Khosla S, Elliot M, Donnelly N. Bilateral otoneurological pathology: To operate or not? Cochlear Implants Int 2017;18(2):121-4.

13) Ogungbo B, Holliman D, Mendelow AD, Hill J. Co-existing cholesteatoma and vestibular schwannoma. J Laryngol Otol 2002; 116(6):460-3.

14) Kucharski A, Szymański M, Szymańska A, Rola R. Diagnosis and management of unilateral cholesteatoma and vestibular schwannoma. Otolaryngology Case Reports 2020;15:100170.

15) Sanna M, Mancini F, Russo A, Taibah A, Falcioni M, Trapani G Di. Atlas of acoustic neurinoma microsurgery. 2nd ed. New York: Thieme;2011. p.60. 